\title{
Upregulation of inducible NO synthase by exogenous adenosine in vascular smooth muscle cells activated by inflammatory stimuli in experimental diabetes
}

Alberto Nassi ${ }^{1,3}$, Francesca Malorgio ${ }^{1}$, Serena Tedesco ${ }^{1}$, Andrea Cignarella ${ }^{2^{*}+}$ and Rosa Maria Gaion ${ }^{1 \dagger}$

\begin{abstract}
Background: Adenosine has been shown to induce nitric oxide $(\mathrm{NO})$ production via inducible NO synthase (iNOS) activation in vascular smooth muscle cells (VSMCs). Although this is interpreted as a beneficial vasodilating pathway in vaso-occlusive disorders, iNOS is also involved in diabetic vascular dysfunction. Because the turnover of and the potential to modulate iNOS by adenosine in experimental diabetes have not been explored, we hypothesized that both the adenosine system and control of iNOS function are impaired in VSMCs from streptozotocin-diabetic rats.
\end{abstract}

Methods: Male Sprague-Dawley rats were injected with streptozotocin once to induce diabetes. Aortic VSMCs from diabetic and nondiabetic rats were isolated, cultured and exposed to lipopolysaccharide (LPS) plus a cytokine mix for $24 \mathrm{~h}$ in the presence or absence of (1) exogenous adenosine and related compounds, and/or (2) pharmacological agents affecting adenosine turnover. iNOS functional expression was determined by immunoblotting and NO metabolite assays. Concentrations of adenosine, related compounds and metabolites thereof were assayed by HPLC. Vasomotor responses to adenosine were determined in endothelium-deprived aortic rings.

Results: Treatment with adenosine-degrading enzymes or receptor antagonists increased iNOS formation in activated VSMCs from nondiabetic and diabetic rats. Following treatment with the adenosine transport inhibitor NBTI, iNOS levels increased in nondiabetic but decreased in diabetic VSMCs. The amount of secreted NO metabolites was uncoupled from iNOS levels in diabetic VSMCs. Addition of high concentrations of adenosine and its precursors or analogues enhanced iNOS formation solely in diabetic VSMCs. Exogenous adenosine and AMP were completely removed from the culture medium and converted into metabolites. A tendency towards elevated inosine generation was observed in diabetic VSMCs, which were also less sensitive to CD73 inhibition, but inosine supplementation did not affect iNOS levels. Pharmacological inhibition of NOS abolished adenosine-induced vasorelaxation in aortic tissues from diabetic but not nondiabetic animals.

Conclusions: Endogenous adenosine prevented cytokine- and LPS-induced iNOS activation in VSMCs. By contrast, supplementation with adenosine and its precursors or analogues enhanced iNOS levels in diabetic VSMCs. This effect was associated with alterations in exogenous adenosine turnover. Thus, overactivation of the adenosine system may foster iNOS-mediated diabetic vascular dysfunction.

Keywords: Adenosine, iNOS, Smooth muscle cells, Vasorelaxation, Purine turnover

\footnotetext{
*Correspondence: andrea.cignarella@unipd.it

${ }^{\dagger}$ Andrea Cignarella and Rosa Maria Gaion contributed equally to this work

${ }^{2}$ Department of Medicine, University of Padova, Padova, Italy

Full list of author information is available at the end of the article
} 


\section{Background}

The pathophysiology of vascular disease associated with diabetes mellitus involves abnormalities in the functions of resident and circulating cells [1] as well as low-grade vascular inflammation with increased cytokine release. Diabetes is associated with altered expression and function of adenosine receptors, which are expressed on most cell types in the cardiovascular system [2]. Increased activity of the adenosine-degrading enzyme adenosine deaminase (ADA) has been also reported in diabetic patients [3] and experimental animals [4], suggesting that alterations in the adenosine system contribute to the pathophysiology of the disease.

Vascular smooth muscle cells (VSMCs) have an active adenosine metabolism [5, 6], and express all known adenosine receptors [7]. Under conditions such as hypoxia, ischaemia or inflammation, the level of extracellular adenosine increases dramatically to improve blood flow via vasodilator $A_{2 A}$ and $A_{2 B}$ receptors expressed on the endothelium and smooth muscle [8]. Adenosine that accumulates in the extracellular compartment, thus reaching its cell surface receptors, can be released as such by means of bidirectional equilibrative nucleoside transporters (ENTs), or formed extracellularly from cell-derived nucleotides that are dephosphorylated by enzymes bound to the external surface of plasma membrane. Among these, ecto- $5^{\prime}$ nucleotidase (CD73) promotes the final conversion of AMP into adenosine. On the other hand, metabolic conversion by ecto-ADA and transport into cells mediated by ENTs and/or concentrative nucleoside transporters account for adenosine removal from the extracellular space $[9,10]$. In VSMCs, $95 \%$ of adenosine transport is mediated by ENT-1 and the rest by ENT-2 [10].

Sustained production of nitric oxide (NO) through the inducible form of NO synthase (iNOS) is a response to a variety of agents including proinflammatory cytokines [11]. VSMCs are endowed with the metabolic machinery that allows release of large amounts of NO in response to cytokines and endotoxin [12-16]. The ability of adenosine to increase basal as well as cytokine- or lipopolysaccharide (LPS)-stimulated NO release in VSMCs is documented [17-19], and it is interpreted as a potential beneficial effect, inasmuch as it would prevent pathologic vaso-occlusion triggered by other local mediators $[20,21]$. On the other hand, the augmented release of NO derived from iNOS is involved in the development of diabetic vascular complications [22-24].

We therefore hypothesized that experimental type I diabetes would alter the modulation of iNOS protein synthesis and activity by exogenous adenosine and agents affecting its turnover in VSMCs. We tested this hypothesis by isolating VSMCs from aortas of diabetic and nondiabetic rats, stimulating VSMCs with LPS combined with a cytokine cocktail in the presence or absence of adenosine and related compounds, and assessing iNOS functional expression as well as adenosine turnover. Our results indicated that, while endogenous adenosine attenuated iNOS production, supplementation with exogenous adenosine was associated with abnormal purine turnover and enhanced iNOS levels in diabetic VSMCs, which may foster diabetic vascular dysfunction.

\section{Methods}

\section{Chemicals and antibodies}

Streptozotocin (STZ) and MRS 1730 were purchased from Tocris Cookson. The anti-iNOS antibody was from BD Biosciences, whereas the peroxidase-coupled secondary antibody was obtained from Vector. Recombinant rat cytokines were obtained from Tebu-Bio. Unless otherwise specified, chemicals were purchased from Sigma-Aldrich.

\section{Animals}

Male Sprague-Dawley rats weighing 200-250 g (Charles River, Italy) were kept in temperature-controlled facilities on a 12-hour light-dark cycle and fed normal chow. At the time of cell or tissue harvest, animals were sacrificed by asphyxia using carbon dioxide. The work described has been carried out in accordance with the EU Directive 2010/63/EU for animal experiments (http://ec.europa.eu/ environment/chemicals/lab_animals/legislation_en.htm).

\section{Diabetes induction}

Diabetes was induced by a single i.p. injection of $65 \mathrm{mg} /$ Kg STZ freshly dissolved in $50 \mathrm{mM}$ citrate buffer $(\mathrm{pH}$ 4.5). Blood glucose was monitored weekly after STZ injection using Glucurtest (Roche Diagnostics). Animals were diabetic for 3 weeks prior to aortic harvest and vascular cell isolation. Only hyperglycemic rats with fasting blood glucose $\geq 11.1 \mathrm{mM}$ were selected for experiments.

\section{Cell culture}

VSMCs from aortic intimal-medial layers were isolated and cultured as previously described [15, 25]. Briefly, VSMCs were synchronized in medium containing $0.4 \%$ FCS for $24 \mathrm{~h}$ and incubated for a further $24 \mathrm{~h}$ where indicated with a cytokine mixture comprising $10 \mathrm{ng} / \mathrm{mL}$ interleukin (IL)- $1 \beta, 10 \mathrm{ng} / \mathrm{mL}$ interferon (IFN) $-\gamma$ and $25 \mathrm{ng} / \mathrm{mL}$ tumor necrosis factor (TNF)- $\alpha$ plus $1 \mu \mathrm{g} / \mathrm{mL}$ LPS. Such a mixture consistently induces iNOS protein formation in VSMCs [25].

\section{Western blotting}

Cultured VSMCs were washed twice with phosphatebuffered saline and extracted directly into lysis buffer 
as described elsewhere [26]. At least $30 \mu \mathrm{g}$ cell protein were loaded onto $10 \%$ SDS-acrylamide gels. Following electrophoresis, proteins were transferred onto HybondECL membranes (GE Healthcare), which were incubated in blocking solution for $2 \mathrm{~h}$ and then with primary antibodies (1:1000) overnight at RT. After washing, the peroxidase-conjugated secondary antibody (1:1000) was applied for $1 \mathrm{~h}$ at RT. After extensive washing, the blots were developed using an enhanced chemiluminescence kit (GE Healthcare). Sample loading control was performed through $\beta$-actin immunodetection. The values of iNOS protein were normalized to those of $\beta$-actin.

\section{Nitrite assay}

The culture medium was collected and centrifuged at $12,000 \mathrm{rpm}$ for $5 \mathrm{~min}$. Next, $250 \mu \mathrm{L} /$ well of medium were treated with $20 \mu \mathrm{l}$ of $6.5 \mathrm{M} \mathrm{HCl}$ and $20 \mu \mathrm{l}$ of $37.5 \mathrm{mM}$ sulfanilic acid in a 96-well plate. After incubation for $10 \mathrm{~min}$, $20 \mu \mathrm{L}$ of $12.5 \mathrm{mM} \mathrm{N}$-(1-naphthyl)-ethylendiamine was added. Optical density was read at $550 \mathrm{~nm}$ after $15 \mathrm{~min}$. Nitrite values were expressed as $\mu \mathrm{mol}$ nitrite/mg cell protein.

\section{Analyses of purine substrates and metabolites}

Adenosine and its metabolites in VSMC culture medium were separated by high-performance liquid chromatography (HPLC) and quantified by UV absorption at $254 \mathrm{~nm}$ as previously described [27]. Briefly, medium samples were neutralized to a $\mathrm{pH}$ of $4-5$ and mixed with $50 \mu \mathrm{M}$ theophylline as internal standard. After centrifugation, supernatants were filtered through a $0.22 \mu \mathrm{m}$ syringe filter. HPLC separation was achieved with a Beckman System Gold Programmable Solvent Module 125 on a Beckman C18 Analytical Ultrasphere column coupled to a Beckman Detector 166, using a non-linear $\mathrm{NaH}_{2} \mathrm{PO}_{4} /$ tetrabutylammonium bromide $(73.5 / 6 \mathrm{mM}, \quad \mathrm{pH}$ 5.8)-methanol (0-25\%) gradient over $38 \mathrm{~min}$, at a flow rate of $1 \mathrm{ml} / \mathrm{min}$. The concentration of adenosine and its metabolites were extrapolated from calibration curves constructed through multiple determinations of standard amounts by plotting the peak areas against the concentration of the sample. Linearity of the assay was assessed using three calibration curves analyzed on separate days. The limit of detection and the lower limit of quantification were above 0.1 and $0.5 \mu \mathrm{M}$, respectively.

\section{Vascular reactivity}

Changes in vasomotor tone of aortic tissues in response to adenosine were recorded in organ chambers. The thoracic aorta was carefully removed, cleaned of fat and connective tissue, and cut into 5-6 $\mathrm{mm}$ rings. Rings were suspended in Krebs-Henselheit solution with the following composition (mM): $\mathrm{NaCl} 118, \mathrm{KCl} 4.7, \mathrm{KH}_{2} \mathrm{PO}_{4} 1.2$,
$\mathrm{MgSO}_{4}$ 1.1, $\mathrm{CaCl}_{2} 2.5, \mathrm{NaHCO}_{3} 25$ and glucose 5.5; pH 7.4, maintained at $37{ }^{\circ} \mathrm{C}$ and continuously aerated with $95 \% \mathrm{O}_{2}, 5 \% \mathrm{CO}_{2}$ for isometric tension recording in organ chambers. In some rings, endothelium was mechanically removed. The rings were connected to isometric tension transducers (Fort 10, World Precision Instruments) coupled with a digital recording system (PowerLab 8SP, ADInstruments). The completeness of endothelial denudation was confirmed by the absence of relaxation to the endothelial-dependent agonist acetylcholine $(1 \mu \mathrm{M})$. After a 90-min equilibration period under a resting tension of $2 \mathrm{~g}$, rings were constricted with $0.1 \mu \mathrm{M}$ norepinephrine, and vasorelaxant responses to adenosine were determined in endothelium-denuded rings. When indicated, rings were previously incubated for $60 \mathrm{~min}$ either with vehicle (control) or the NO synthase inhibitor $\mathrm{N}^{\mathrm{G}_{-}}$ monomethyl-L-arginine (L-NMA; $10 \mu \mathrm{M})$.

\section{Statistical analysis}

Data are expressed as mean \pm SEM, or as percentage, where appropriate. Comparison between 2 or more groups was performed using the Student's $t$ test and ANOVA, respectively. Linear correlations were checked using the Pearson's $r$ coefficient. Statistical analysis was accepted at $P<0.05$ and SPSS ver. 21.0 was used.

\section{Results}

Influence of endogenous adenosine on iNOS synthesis and activity in VSMCs from diabetic rats and normoglycemic controls

We previously reported that iNOS expression and release of NO metabolites in response to 24-h stimulation with LPS and cytokines are attenuated by about $30 \%$ in cultured VSMCs from STZ-diabetic rats as compared to those from normoglycemic rats $[15,28]$. In the absence of inflammatory stimuli, iNOS is undetectable in these cells $[15,28]$. This pattern was confirmed in the present study. In fact, at the end of a 24-h incubation of control or diabetic VSMCs in the presence of LPS and cytokines, which reproduce a setting of vascular inflammation, iNOS became detectable by Western blot (Fig. 1). Treatment with ADA to remove endogenous adenosine from the incubation medium enhanced the iNOS response to LPS/cytokines in both control and diabetic VSMCs. This effect was mimicked by the nonselective adenosine receptor antagonist 8-phenyltheophylline (8-PT; Fig. 1a, b).

In stimulated VSMCs from nondiabetic rats, the adenosine deaminase inhibitor erythro-9-(2-Hydroxy-3nonyl)adenine (EHNA) reduced iNOS synthesis while the ENT inhibitor S-(4-Nitrobenzyl)-6-thioinosine (NBTI) enhanced it, and the CD73 inhibitor $\alpha, \beta$-MethyleneADP (AOPCP) was ineffective (Fig. 2a). In VSMCs from 


\section{a}
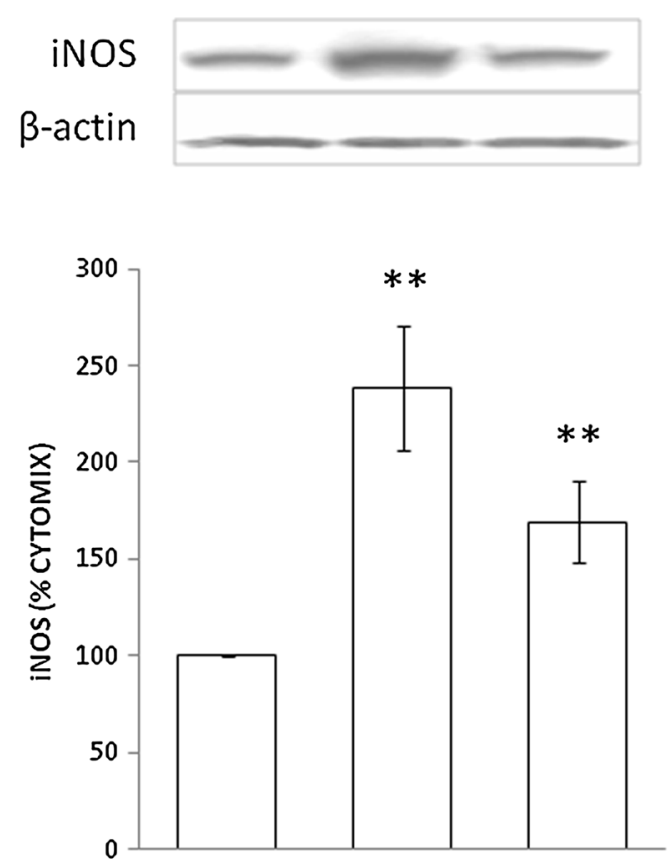

\section{ADA $1 U$}

8-PT10 $\mu \mathrm{M}$ b
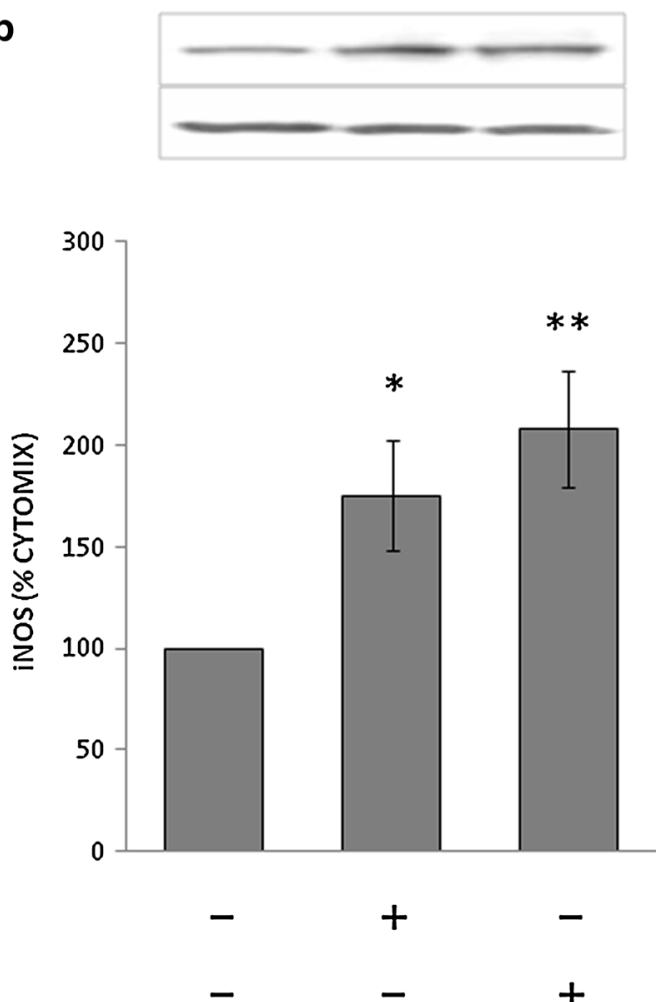

Fig. 1 Immunoblots for iNOS in VSMCs from control (a) and STZ-diabetic rats (b) in the presence of endogenous adenosine modulators. VSMCs were incubated with cytomix comprising $10 \mathrm{ng} / \mathrm{mL}$ interleukin (IL)- $1 \beta, 10 \mathrm{ng} / \mathrm{mL}$ interferon (IFN)- $\gamma$ and $25 \mathrm{ng} / \mathrm{mL}$ tumor necrosis factor (TNF)-a plus $1 \mathrm{\mu g} / \mathrm{mL}$ LPS for $24 \mathrm{~h}$. Representative blots are shown. Densitometric analysis of iNOS protein levels are shown as \% cytomix. The data are presented as mean $\pm \operatorname{SEM}(n=8) .{ }^{*} P<0.05,{ }^{* *} P<0.01$ (two-tailed $t$-test). ADA, adenosine deaminase; 8-PT, 8-phenyltheophylline

diabetic rats, under the same experimental conditions, EHNA did not cause any significant change in iNOS protein level. In contrast, AOPCP and NBTI partially prevented iNOS formation (Fig. 2b).

In the above experiments, measurement of NO metabolites' accumulation in the culture medium showed a direct and significant correlation between iNOS protein levels and enzyme activity in control VSMCs, which was disrupted in diabetic VSMCs (Fig. 3).

\section{Influence of exogenous adenosine on iNOS production}

Under stimulation with LPS/cytokines, addition of adenosine did not alter iNOS levels in control VSMCs, while a significant $60 \%$ increase was observed in diabetic VSMCs at the highest concentration tested (Table 1). In the presence of exogenous adenosine, iNOS protein levels were not affected by addition of EHNA or NBTI. Similarly, AOPCP did not alter the iNOS response to exogenous AMP (Table 1). Pretreatment of diabetic VSMCs with MRS1706 (0.1 $\mu \mathrm{M}, \mathrm{A}_{2 \mathrm{~B}}$ selective antagonist) significantly decreased adenosine-induced iNOS accumulation, in line with previous reports showing a prominent role for the $\mathrm{A}_{2 \mathrm{~B}}$ receptor pathway $[18,19]$.
In these experiments the nucleoside measured in the medium after incubation was in the submicromolar range, often below the detection limit of our HPLC method (Fig. 4). When adenosine was measured immediately after its addition to the incubation medium (time zero, not shown), its recovery was close to $100 \%$ (e.g. $99 \pm 2 \mu \mathrm{M}$ and $99 \pm 1 \mu \mathrm{M}$ in control and diabetic VSMCs, respectively, for $100 \mu \mathrm{M}$ adenosine, $n=3$ ).

Similar to $100 \mu \mathrm{M}$ adenosine, the ADA-resistant adenosine derivative, phenylisopropyladenosine (PIA), as well as the direct precursor AMP increased iNOS protein level in diabetic VSMCs but were ineffective in those from control animals (Fig. 5). The deamination product of adenosine, inosine, did not alter iNOS levels in either cell type (Fig. 5).

\section{Turnover of exogenous adenosine}

Cultured VSMCs release purine and pyrimidine nucleosides and their metabolites into external medium under basal conditions [5]. In the medium of VSMCs incubated for $24 \mathrm{~h}$ with or without LPS/cytokines, the only detectable metabolite was hypoxanthine: $14.2 \pm 1.4$ and $12.0 \pm 3.6 \mu \mathrm{M}$, respectively, in control VSMCs; $11.7 \pm 1.9$ 

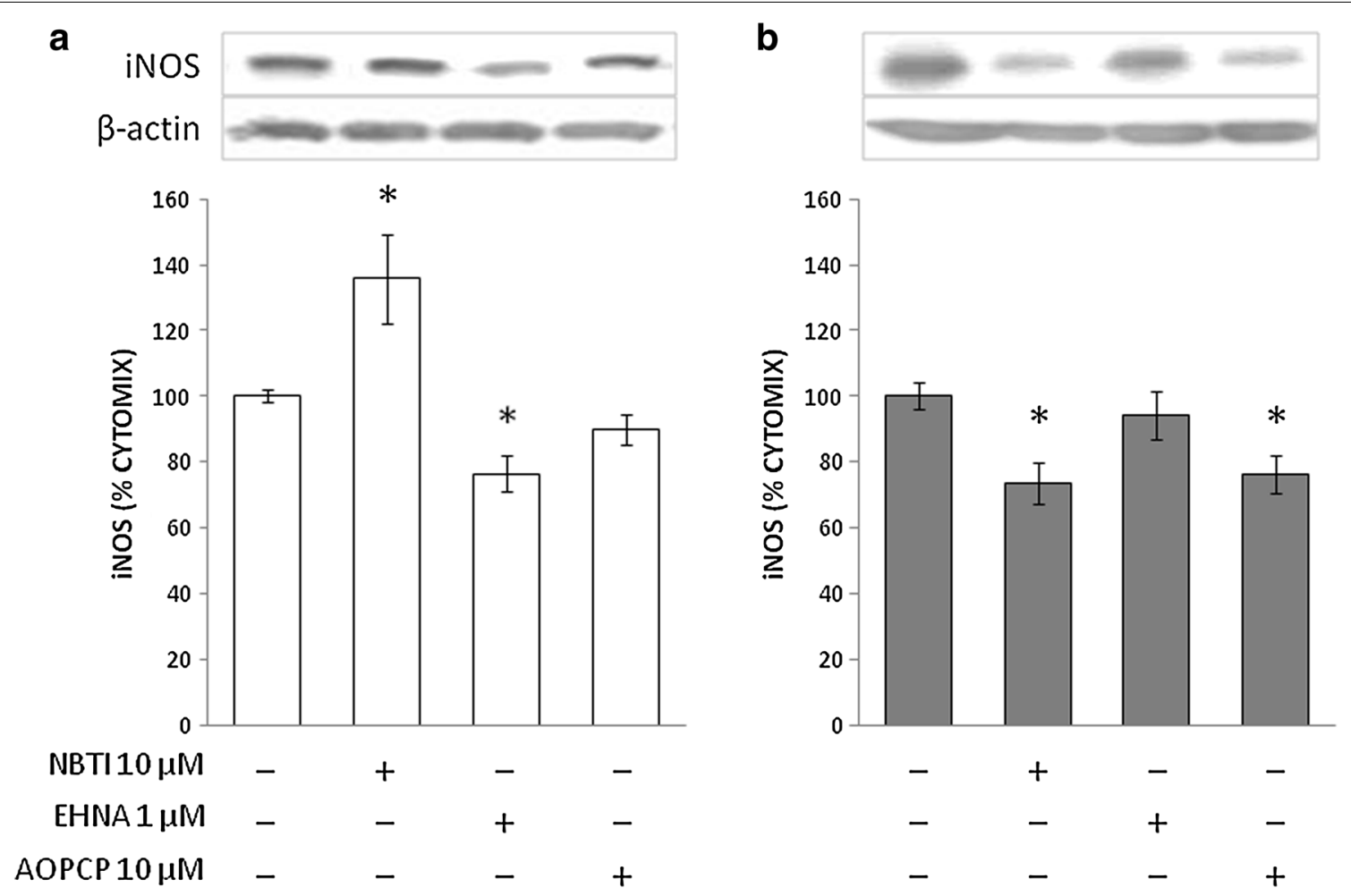

Fig. 2 Immunoblots for iNOS in VSMCs from control (a) and STZ-diabetic rats (b) in the presence of adenosine turnover modulators. VSMCs were incubated as described in the legend to Fig. 1. Representative blots are shown. Densitometric analysis of iNOS protein levels are shown as \% cytomix. The data are presented as mean \pm SEM $(n=8) .{ }^{*} P<0.05$ (two-tailed $t$-test). NBTI, S-(4-Nitrobenzyl)-6-thioinosine; EHNA, erythro-9-(2-Hydroxy-3nonyl)adenine; AOPCP, a, $\beta$-Methylene-ADP
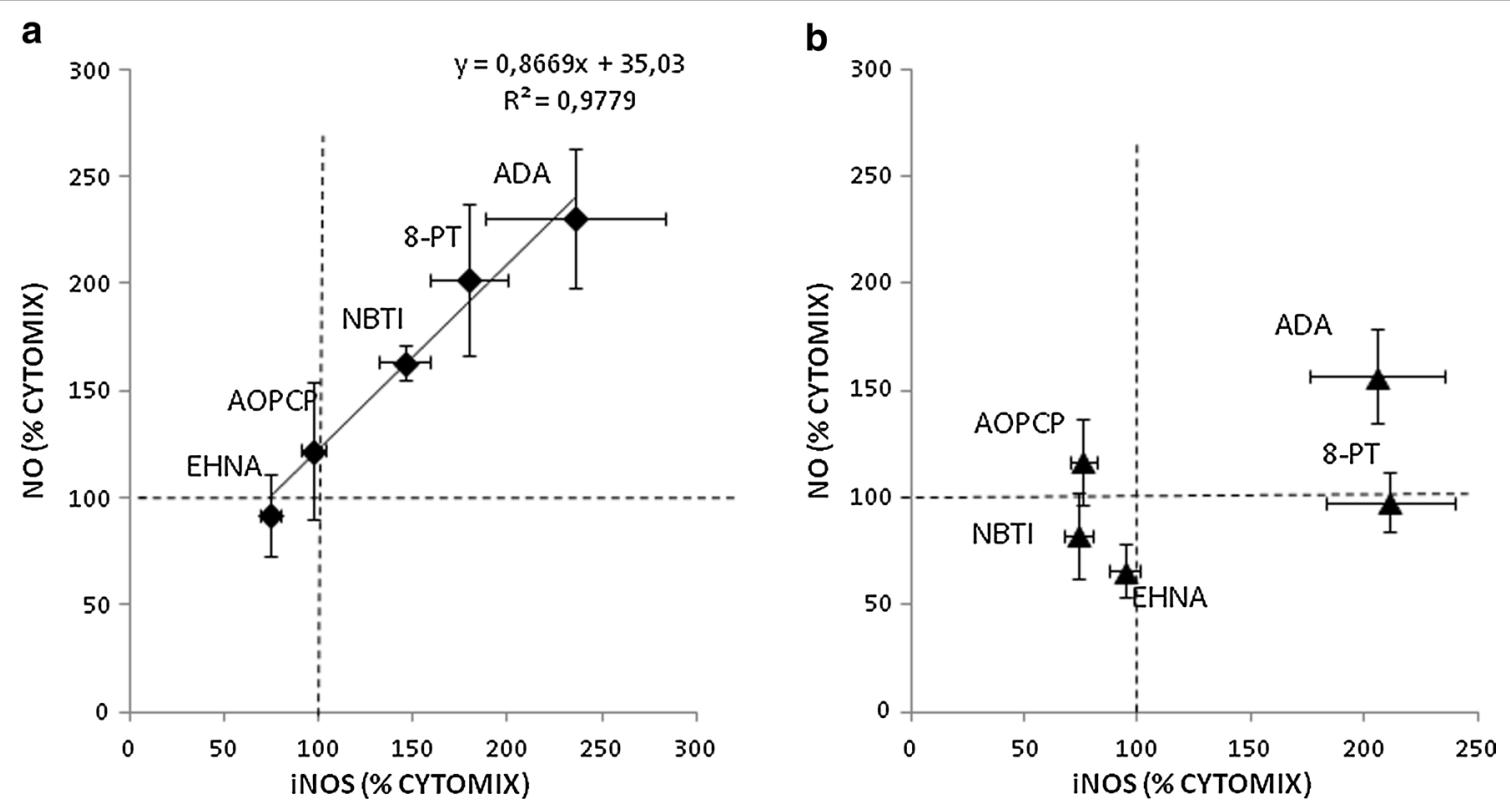

Fig. 3 Correlations between iNOS levels and NO metabolite release into the culture medium of VSMCs from control (a) and STZ-diabetic rats (b). iNOS level data are from experiments shown in Figs. 1 and 2 
Table 1 Effects of exogenous adenosine/AMP on cytokineinduced iNOS synthesis in aortic smooth muscle cells

\begin{tabular}{|c|c|c|}
\hline & \multicolumn{2}{|c|}{$\begin{array}{l}\text { Relative densitometric analysis } \\
\text { of iNOS levels (arbitrary units) }\end{array}$} \\
\hline & Control $(n=7)$ & Diabetes $(n=8)$ \\
\hline No addition & $100 \pm 8$ & $100 \pm 12$ \\
\hline Adenosine $1 \mu \mathrm{M}$ & $95 \pm 12$ & $91 \pm 7$ \\
\hline Adenosine $10 \mu \mathrm{M}$ & $90 \pm 12$ & $114 \pm 7$ \\
\hline Adenosine $100 \mu \mathrm{M}$ & $97 \pm 9$ & $161 \pm 14^{*}$ \\
\hline Adenosine $100 \mu \mathrm{M}+$ EHNA $1 \mu \mathrm{M}$ & $112 \pm 10$ & $152 \pm 14^{*}$ \\
\hline Adenosine $100 \mu \mathrm{M}+\mathrm{NBTI} 10 \mu \mathrm{M}$ & $93 \pm 10$ & $154 \pm 22^{*}$ \\
\hline $\begin{array}{l}\text { Adenosine } 100 \mu \mathrm{M}+\mathrm{MRS} 1706 \\
1 \mu \mathrm{M}^{\mathrm{a}}\end{array}$ & $90 \pm 15$ & $108 \pm 11^{* *}$ \\
\hline AMP $100 \mu \mathrm{M}$ & $108 \pm 6$ & $150 \pm 12^{*}$ \\
\hline AMP $100 \mu \mathrm{M}+$ AOPCP $200 \mu \mathrm{M}$ & $115 \pm 9$ & $176 \pm 19^{*}$ \\
\hline
\end{tabular}

Rat aortic smooth muscle cells from control and diabetic rats were incubated with $10 \mathrm{ng} / \mathrm{mL}$ interleukin (IL)- $1 \beta, 10 \mathrm{ng} / \mathrm{mL}$ interferon (IFN)- $\gamma$ and $25 \mathrm{ng} / \mathrm{mL}$ tumor necrosis factor (TNF)-a plus $1 \mu \mathrm{g} / \mathrm{mL}$ LPS for $24 \mathrm{~h}$. iNOS was detected by Western blot. Densitometric analysis of protein level is expressed as \% of No addition

EHNA erythro-9-(2-Hydroxy-3-nonyl)adenine, NBTI S-(4-Nitrobenzyl)-6thioinosine, $A O P C P$ a, $\beta$-Methylene-ADP

${ }^{*} \mathrm{P}<0.01$ vs. No addition, ${ }^{* *} \mathrm{P}<0.05$ vs. Adenosine $100 \mu \mathrm{M}$ (two-tailed $t$ test)

a $n=3$

and $10.8 \pm 2.1 \mu \mathrm{M}$, respectively, in diabetic VSMCs $(n=4)$.

As observed with adenosine (Fig. 4), AMP was efficiently cleared from the medium: both AMP and adenosine were undetectable after $24 \mathrm{~h}$ (Fig. 6). By contrast, exogenous inosine was only partially removed as its concentration accounted for more than $25 \%$ of the nucleoside added at the beginning of the experiments in nondiabetic VSMCs, and this fraction increased to almost $45 \%$ in diabetes (Fig. 6). Interestingly, for both cell types, these inosine concentrations were not significantly different from those recovered upon incubation with adenosine but were higher than those resulting from AMP degradation (Fig. 6). Adenosine, AMP and inosine were further converted into hypoxanthine, whose accumulation equalled $48-51 \%$ of added substrates in control VSMCs. In diabetic VSMCs this fraction was comparable when adding AMP as a substrate, but decreased to less than $30 \%$ when cells were incubated with adenosine or inosine (Fig. 6). The same incubations were performed also in the absence of cells, in order to detect spontaneous degradation and/or identify any bias related to possible ADA, 5'-nucleotidase and/or purine nucleoside phosphorylase (PNP) activity associated with FCS in the culture medium. Indeed, detectable amounts of inosine were also measured in samples incubated with AMP or adenosine. About half of exogenous AMP was converted to adenosine, while hypoxanthine concentrations did not differ from baseline levels (Fig. 6c). Treatment with pharmacological inhibitors did not enhance endogenous adenosine or AMP to detectable levels (data not shown).

In the presence of exogenous adenosine, EHNA and, to a lesser extent, NBTI reduced the purine clearance, allowing its partial recovery in the medium, which was quantitatively similar for diabetic and control VSMCs (Fig. 7). By contrast, in those samples in which AMP was combined with AOPCP, the amount of recovered AMP accounted for half of the nucleotide added to control VSMCs, but for less than $10 \%$ in experiments with
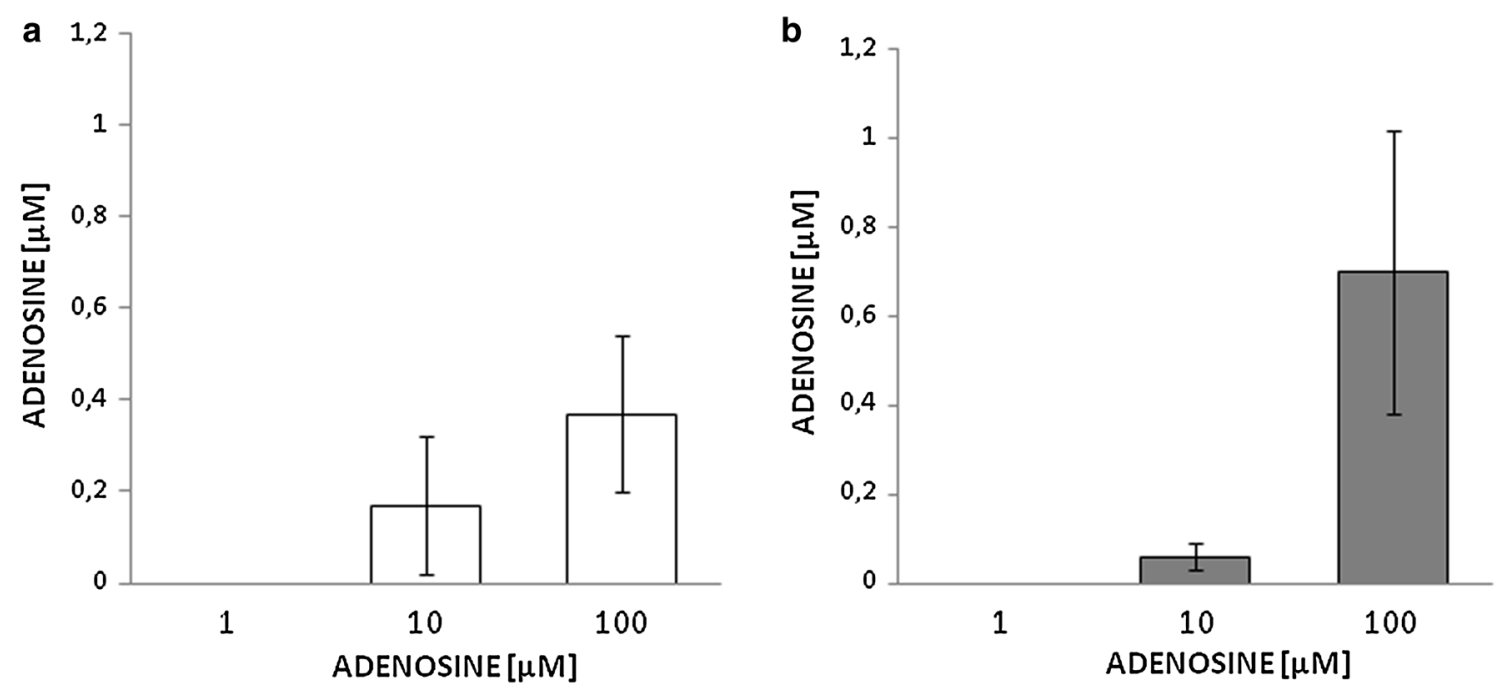

Fig. 4 Residual adenosine concentration as measured by HPLC in the culture medium of VSMCs from control (a) and STZ-diabetic rats (b) following incubation with increasing adenosine concentrations $(1-100 \mu \mathrm{M})$ for $24 \mathrm{~h}$. The values represent the mean $\pm \mathrm{SEM}(\mathrm{n}=10)$ 

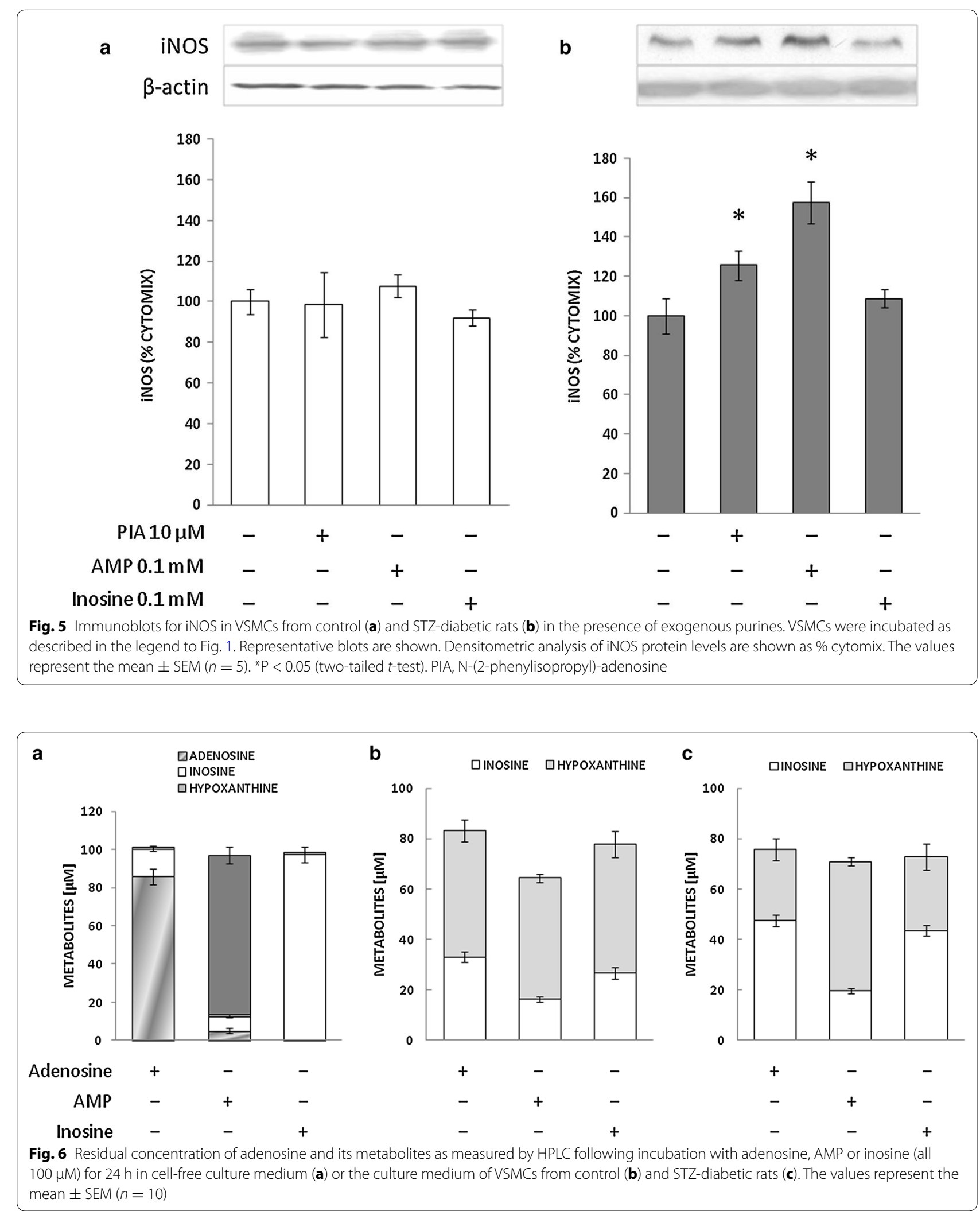
diabetic VSMCs (Fig. 7), indicating that diabetes markedly reduced $C D 73$ sensitivity to pharmacological inhibition by AOPCP.

\section{Adenosine-induced relaxation of endothelium-denuded aortic rings}

In order to access a possible role of smooth muscle NOS in the vasorelaxant effect of adenosine, ex vivo experiments were performed on rings of endothelium-denuded rat aorta pre-contracted with norepinephrine. Under these conditions acetylcholine barely affected vascular tone $(-10.5 \pm 2.4$, and $-11.2 \pm 4.9 \%$, change in norepinephrine-induced tension in preparations from control and diabetic rats, respectively; $N S, n=3$ ), while adenosine significantly relaxed vascular tissues by up to $25.1 \pm 5.4$ and $35.3 \pm 4.6 \%$ in diabetic and control preparations, respectively (Fig. 8). Interestingly, pre-treatment with L-NMA abolished the vasorelaxant effect of adenosine in diabetic but not in nondiabetic aortic tissues (Fig. 8).

\section{Discussion}

Diabetes affects the modulation of VSMC function by adenosine. For instance, primary cultures of aortic VSMCs obtained from rats with streptozotocin-induced diabetes mellitus have a greater susceptibility to the inhibitory effects of adenosine on cell proliferation [29]. Our results showed alterations in adenosine turnover

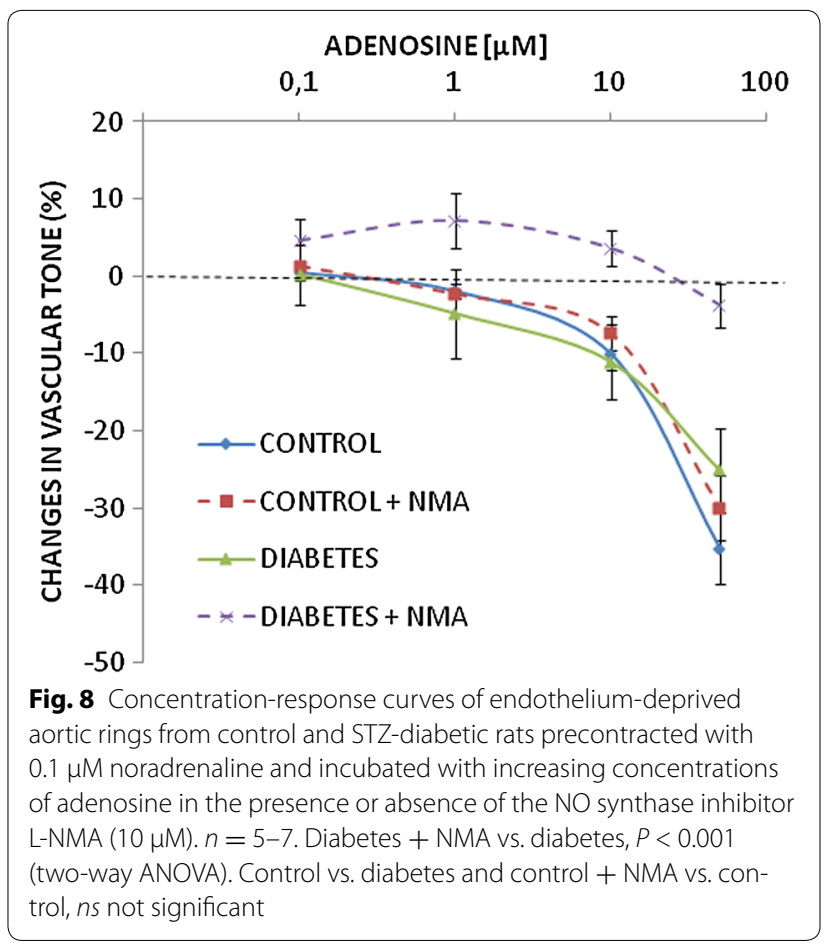

and modulation of iNOS synthesis in the same cell model that can be relevant in the setting of diabetic vascular dysfunction.
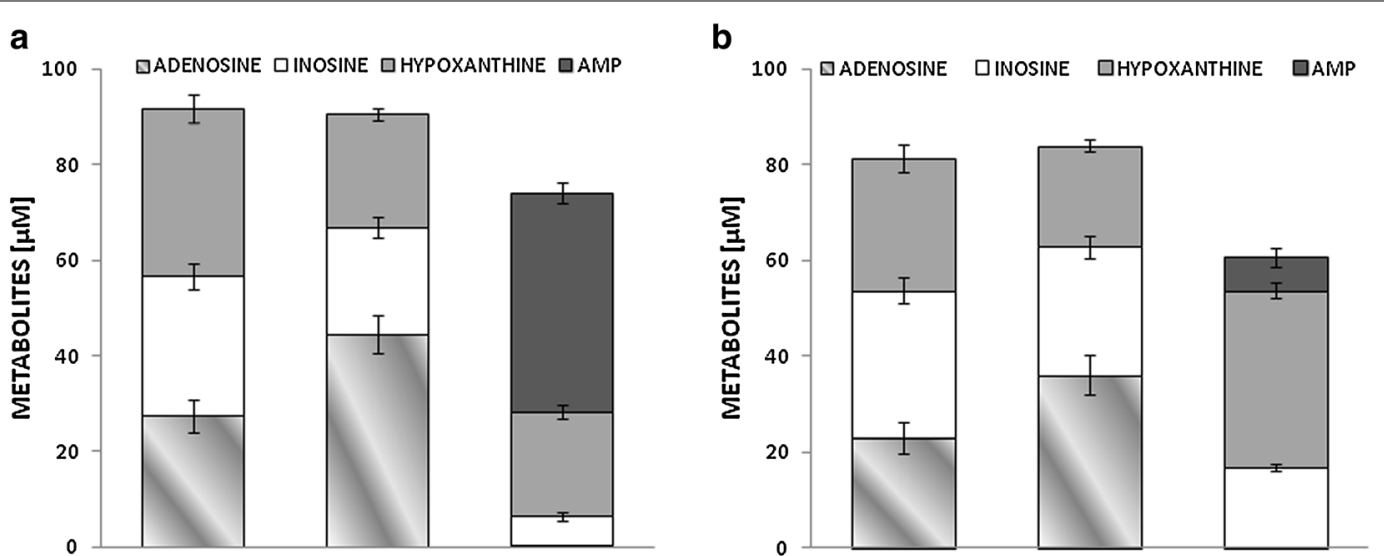

\begin{tabular}{|c|}
\hline \multirow{2}{*}{$\begin{array}{l}\text { osine } 100 \mu \mathrm{M} \\
\text { AMP } 100 \mu \mathrm{M}\end{array}$} \\
\hline \\
\hline EHNA $1 \mu \mathrm{M}$ \\
\hline $\mathrm{NBTI} 10 \mu \mathrm{M}$ \\
\hline АОРСР $10 \mu \mathrm{M}$ \\
\hline
\end{tabular}
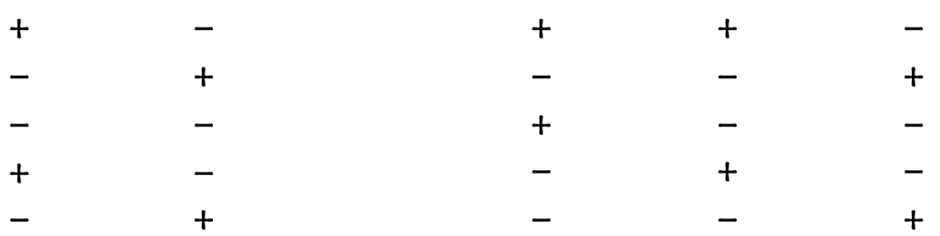

Fig. 7 Residual concentration of adenosine, AMP and metabolites thereof as measured by HPLC following incubation with adenosine or AMP (both $100 \mu \mathrm{M})$ for $24 \mathrm{~h}$ in the culture medium of VSMCs from control (a) and STZ-diabetic rats (b). Inhibitors of adenosine/AMP turnover were added as indicated. The values represent the mean $\pm \operatorname{SEM}(n=6)$. NBTI, S-(4-Nitrobenzyl)-6-thioinosine; EHNA, erythro-9-(2-Hydroxy-3-nonyl)adenine; AOPCP, a, $\beta$-methylene-ADP 
Regulation of iNOS functional expression by endogenous vs. exogenous adenosine

We found that endogenous adenosine impairs LPS/ cytokine-induced iNOS formation in VSMCs, as shown by iNOS upregulation following treatment with ADA and with the nonspecific adenosine receptor antagonist 8-PT. Similarly, the ENT1 inhibitor NBTI enhanced iNOS accumulation in control VSMCs, in line with the observation that the adenosine uptake inhibitor dipyridamole up-regulates the IL- $1 \beta$-induced NO production in a dose-dependent manner [30]. Under inflammatory conditions adenosine was released through ENTs in control VSMCs, whereas the transport direction appeared to be reversed in diabetic VSMCs. It has been speculated that increased ENT-1 activity as described in vitro in human SMCs exposed to hyperglycemia [31] or isolated from diabetic patients [32] may reduce adenosine availability to its receptors, thereby weakening the vascular functions of adenosine [10]. In diabetes, ENT-mediated transport is the main mechanism that cleared extracellular adenosine, while under control conditions ADA played a greater functional role. In the presence of the 5 '-ectonucleotidase inhibitor AOPCP, extracellular AMP could achieve concentrations that mimicked the effects of adenosine on iNOS.

In contrast to previous reports [17-19], we were unable to detect increased iNOS functional expression by exogenous adenosine in VSMC from normoglycemic rats. Because either LPS or IL-1 $\beta$ alone were used to activate VSMCs in those studies, it is conceivable that the LPS/ cytokine cocktail as used in the present study induced maximal iNOS activation via cyclic AMP [13] that could not be further enhanced by adenosine as described in the above-mentioned studies. However, we found that diabetes enhanced VSMC sensitivity to high concentrations of exogenous adenosine in terms of LPS/cytokineinduced iNOS production. To the best of our knowledge this finding is novel, and was likely determined by functional abnormality in Gi activity as described previously in VSMCs from diabetic rats [29] or activation of second messengers other than cAMP by high adenosine concentrations as suggested by others [17]. Because stimulated diabetic rat-derived VSMCs express less iNOS than control VSMC at earlier time points [15, 28] (Fig. 1), the increase in iNOS seen with $100 \mu \mathrm{M}$ adenosine (Table 1) may be viewed as a short-term compensatory and beneficial effect. Whether exogenous adenosine affects the delayed response to long-term cytokine stimulation previously reported to occur in diabetic VSMCs [15] requires further investigation.

Unlike in control VSMCs, iNOS formation and NO release were found to be uncoupled in VSMCs from diabetic rats. Post-translational iNOS regulation may occur via several mechanisms including homodimerization by NOS-associated protein $1.10 \mathrm{kd}$ (NAP110; [33]) or specific trafficking and activity regulation by multifunctional $\mathrm{Ca}^{2+} /$ calmodulin-dependent protein kinase II (CaMKII; [34]). As the latter mechanism has been shown to be upregulated in VSMCs from diabetic rats [24], the observed uncoupling may be due to enhanced intracellular nitrotyrosine generation that is undetectable in the culture medium. This may represent a mechanism of cell/ tissue injury involved in diabetic vascular dysfunction.

\section{Functional implications of perturbed NO levels in diabetes}

Attenuated adenosine-mediated endothelium-dependent vasodilatation has been demonstrated in diabetic patients [35]. In agreement with previous studies [36], however, we found no abnormality in the relaxant response to adenosine of endothelium-denuded aortic rings due to diabetes. Our experiments in aortic rings not exposed to exogenous inflammatory stimuli (Fig. 8) suggest that smooth muscle NOS contributed significantly to adenosine-mediated vasorelaxation in vessels from diabetic but not nondiabetic rats, most likely due to increased iNOS expression in diabetic vessels $[37,38]$.

It should be pointed out that activation of NO synthase in diabetes is a multifactorial issue. For instance, overexpression of SIRT1 reduces diabetes-exacerbated myocardial ischemia-reperfusion injury and oxidative stress via activating eNOS in diabetic rats [39], and the vasculoprotective effect of insulin after arterial injury is mediated by an eNOS-dependent mechanism [40]. On the other hand, excess NO impairs glycemic control by diminishing insulin-stimulated muscle glucose uptake [41]. People with diabetes tend to have lower global levels of NO [42]. Therefore, beyond contributing to the homeostasis of the vasculature, $\mathrm{NO}$ is a key signaling molecule for insulin action and glucose disposal.

\section{Adenosine metabolism and turnover are altered in diabetic rat-derived VSMCs}

With regard to major purine-inactivating pathways, ADA and CD73 were remarkably active in both control and diabetic VSMCs, with no residual AMP or adenosine found in the medium $24 \mathrm{~h}$ after supplementation. We also found a tendency to increased inosine generation following adenosine supplementation by diabetic VSMCs, possibly as a result of increased ADA activity, as described in diabetic patients [43] and in experimental models of hypertension [44]. Residual inosine concentrations following inosine supplementation to diabetic VSMCs were also higher than in control VSMCs. Thus, the enzyme PNP, which generates hypoxanthine from inosine, appeared to be the rate limiting step in adenosine catabolism, with somewhat lower activity in diabetic 
compared with control VSMCs. Yet supplementation of inosine, unlike that of adenosine, had no effect on iNOS synthesis in diabetic VSMCs. Overall, these findings point to alterations in the degradation pathways of exogenous purines in diabetes, which may have functional implications in VSMC function.

\section{Conclusions}

To sum up, iNOS production induced by inflammatory stimuli was attenuated by endogenous adenosine in VSMCs, whereas addition of high concentrations of adenosine and its precursors/analogues enhanced iNOS production in diabetic compared with nondiabetic VSMCs. While it may be viewed as a compensatory and beneficial effect, the increase in iNOS mediated by exogenous adenosine was associated with abnormal purine turnover. Hence, NO-related alterations in adenosine metabolism and anti-inflammatory pathways may be involved in diabetic vascular dysfunction.

\begin{abstract}
Abbreviations
ADA: adenosine deaminase; AOPCP: a, B-Methylene-ADP; EHNA: erythro-9-(2Hydroxy-3-nonyl)adenine; ENT: equilibrative nucleoside transporters; L-NMA: $\mathrm{N}^{\mathrm{G}}$-monomethyl-L-arginine; LPS: lipopolysaccharide; NBTI: S-(4-Nitrobenzyl)6-thioinosine; PIA: phenylisopropyladenosine; PNP: purine nucleoside phosphorylase; STZ: streptozotocin; VSMC: vascular smooth muscle cells.
\end{abstract}

\section{Authors' contributions}

AN performed cell culture experiments, vascular reactivity experiments and diabetes induction; FM performed HPLC assays; ST performed cell culture experiments; AC supervisor, wrote manuscript; RMG supervisor, wrote draft and planned the study. All authors read and approved the final manuscript.

\section{Author details}

${ }^{1}$ Department of Pharmaceutical and Pharmacological Sciences, University of Padova, Padova, Italy. ${ }^{2}$ Department of Medicine, University of Padova, Padova, Italy. ${ }^{3}$ Present Address: Transplant Immunology Unit, Padua University Hospital, Padova, Italy.

\section{Acknowledgements}

This work was supported by Grants from the University of Padua to AC (No. CPDA108340) and RMG (No. CPDA071492).

\section{Competing interests}

The authors declare that they have no competing interests.

\section{Ethical approval}

The project involving experiments on animals was assessed by the competent authority at the University of Padova and received a positive assessment (nr. 8 Bis/2012) on April 23, 2012.

Received: 27 October 2015 Accepted: 2 February 2016

Published online: 16 February 2016

\section{References}

1. Creager MA, Lüscher TF, Cosentino F, Beckman JA. Diabetes and vascular disease: pathophysiology, clinical consequences, and medical therapy: part I. Circulation. 2003;108:1527-32.

2. Antonioli L, Blandizzi C, Csóka B, Pacher P, Haskó G. Adenosine signalling in diabetes mellitus - pathophysiology and therapeutic considerations. Nat Rev Endocrinol. 2015;11:228-41.
3. Hoshino T, Yamada K, Masuoka K, Tsuboi I, Itoh K, Nonaka K, Oizumi K. Elevated adenosine deaminase activity in the serum of patients with diabetes mellitus. Diabetes Res Clin Pract. 1994;25:97-102.

4. Rücker B, Abreu-Vieira G, Bischoff LB, Harthmann ÂD, Sarkis JJ, Wink MR, Casali EA. The nucleotide hydrolysis is altered in blood serum of streptozotocin-induced diabetic rats. Arch Physiol Biochem. 2010;116:79-87.

5. James SG, Appleby GJ, Miller KA, Steen JT, Colquhoun EQ, Clark MG. Purine and pyrimidine nucleotide metabolism of vascular smooth muscle cells in culture. Gen Pharmacol. 1996;27:837-44.

6. Mattig S, Deussen A. Significance of adenosine metabolism of coronary smooth muscle cells. Am J Physiol Heart Circ Physiol. 2001;280:H117-24.

7. Zhao Z, Francis CE, Ravid K. An A3-subtype adenosine receptor is highly expressed in rat vascular smooth muscle cells: its role in attenuating adenosine-induced increase in CAMP. Microvasc Res. 1997;54:243-52.

8. Burnstock G, Ralevic V. Purinergic signaling and blood vessels in health and disease. Pharmacol Rev. 2013;66:102-92.

9. Löffler M, Morote-Garcia JC, Eltzschig SA, Coe IR, Eltzschig HK. Physiological roles of vascular nucleoside transporters. Arterioscler Thromb Vasc Biol. 2007;27:1004-13.

10. Li RW, Yang C, Sit AS, Lin SY, Ho EY, Leung GP. Physiological and pharmacological roles of vascular nucleoside transporters. J Cardiovasc Pharmacol. 2012;59:10-5.

11. Dinerman JL, Lowenstein CJ, Snyder SH. Molecular mechanisms of nitric oxide regulation- potential relevance to cardiovascular disease. Circ Res. 1993;73:217-22.

12. Beasley D, Schwartz JH, Brenner BM. Interleukin 1 induces prolonged L-arginine-dependent cyclic guanosine monophosphate and nitrite production in rat vascular smooth muscle cells. J Clin Invest. 1991;87:602-8.

13. Hecker M, Cattaruzza M, Wagner AH. Regulation of inducible nitric oxide synthase gene expression in vascular smooth muscle cells. Gen Pharmacol. 1999;32:9-16.

14. Ginnan R, Guikema BJ, Halligan KE, Singer HA, Jourd'heuil D. Regulation of smooth muscle by inducible nitric oxide synthase and NADPH oxidase in vascular proliferative diseases. Free Radic Biol Med. 2008;44:1232-45.

15. Maggi A, Cignarella A, Brusadelli A, Bolego C, Pinna C, Puglisi L. Diabetes undermines estrogen control of inducible nitric oxide synthase function in rat aortic smooth muscle cells through overexpression of estrogen receptor- $\beta$. Circulation. 2003;108:211-7.

16. Teng X, Zhang H, Snead C, Catravas JD. Molecular mechanisms of iNOS induction by IL-1 $\beta$ and IFN- $\gamma$ in rat aortic smooth muscle cells. Am J Physiol Cell Physiol. 2002;282:C144-52.

17. Seo HG, Fujii J, Asahi M, Okado A, Fujiwara N, Taniguchi N. Roles of purine nucleotides and adenosine in enhancing NOS II gene expression in interleukin-1 $\beta$-stimulated rat vascular smooth muscle cells. Free Radic Res. 1997;26:409-18.

18. Ikeda U, Kurosaki K, Ohya K, Shimada K. Adenosine stimulates nitric oxide synthesis in vascular smooth muscle cells. Cardiovasc Res. 1997;35:168-74.

19. Dubey RK, Gillespie DG, Jackson EK. Cyclic AMP-adenosine pathway induces nitric oxide synthesis in aortic smooth muscle cells. Hypertension. 1998;31:296-302.

20. Riksen NP, Rongen GA, Yellon D, Smits P. Human in vivo research on the vascular effects of adenosine. Eur J Pharmacol. 2008;585:220-7.

21. Ralevic V, Dunn WR. Purinergic transmission in blood vessels. Auton Neurosci. 2015;191:48-66.

22. Chen H, Brahmbhatt S, Gupta A, Sharma AC. Duration of streptozotocininduced diabetes differentially affects p38-mitogen-activated protein kinase (MAPK) phosphorylation in renal and vascular dysfunction. Cardiovasc Diabetol. 2005:4:3.

23. Nagareddy PR, Xia Z, McNeill JH, MacLeod KM. Increased expression of iNOS is associated with endothelial dysfunction and impaired pressor responsiveness in streptozotocin-induced diabetes. Am J Physiol. 2005;289:H2144-52.

24. Di Pietro N, Di Tomo P, Di Silvestre S, Giardinelli A, Pipino C, Morabito C, et al. Increased iNOS activity in vascular smooth muscle cells from diabetic rats: potential role of $\mathrm{Ca}^{2+} /$ calmodulin-dependent protein kinase II delta 2 (CaMKIII2). Atherosclerosis. 2013;226:88-94

25. Zancan V, Santagati S, Bolego C, Vegeto E, Maggi A, Puglisi L. 17ß-estradiol decreases nitric oxide synthase II synthesis in vascular smooth muscle cells. Endocrinology. 1999;140:2004-9. 
26. Idel S, Ellinghaus P, Wolfrum C, Nofer JR, Gloerich J, Assmann G, et al. Branched chain fatty acids induce nitric oxide-dependent apoptosis in vascular smooth muscle cells. J Biol Chem. 2002;277:49319-25.

27. Giron MC, Bin A, Brun P, Etteri S, Bolego C, Florio C, Gaion RM. Cyclic AMP in rat ileum: evidence for the presence of an extracellular cyclic AMPadenosine pathway. Gastroenterology. 2008;134:1116-26.

28. Cignarella A, Bolego C, Pelosi V, Meda C, Krust A, Pinna C, Gaion RM, Vegeto $E$, Maggi A. Distinct roles of estrogen receptor- $a$ and $B$ in the modulation of vascular inducible $\mathrm{NO}$ synthase in diabetes. J Pharmacol Exp Ther. 2009;328:174-82

29. Parés-Herbuté N, Hillaire-Buys D, Etienne P, Gross R, Loubatières-Mariani MM, Monnier L. Adenosine inhibitory effect on enhanced growth of aortic smooth muscle cells from streptozotocin-induced diabetic rats. $\mathrm{Br} J$ Pharmacol. 1996;118:783-9.

30. limura O, Kusano E, Amemiya M, Muto S, Ikeda U, Shimada K, Asano Y. Dipyridamole enhances interleukin-1 $\beta$-stimulated nitric oxide produc tion by cultured rat vascular smooth muscle cells. Eur J Pharmacol. 1996;296:319-26.

31. Leung GP, Man RY, Tse CM. D-Glucose upregulates adenosine transport in cultured human aortic smooth muscle cells. Am J Physiol Heart Circ Physiol. 2005;288:H2756-62.

32. Aguayo C, Sobrevia L. Nitric oxide, cGMP and CAMP modulate nitrobenzylthioinosine-sensitive adenosine transport in human umbilical artery smooth muscle cells from subjects with gestational diabetes. Exp Physiol. 2000;85:399-409.

33. Ratovitski EA, Bao C, Quick RA, McMillan A, Kozlovsky C, Lowenstein CJ. An inducible nitric-oxide synthase (NOS)-associated protein inhibits NOS dimerization and activity. J Biol Chem. 1999;274:30250-7.

34. Jones RJ, Jourd'heuil D, Salerno JC, Smith SM, Singer HA. iNOS regulation by calcium/calmodulin-dependent protein kinase II in vascular smooth muscle. Am J Physiol Heart Circ Physiol. 2007;292:H2634-42.

35. Thaning P, Bune LT, Hellsten Y, Pilegaard H, Saltin B, Rosenmeier JB. Attenuated purinergic receptor function in patients with type 2 diabetes. Diabetes. 2010;59:182-9.
36. Fahim M, Hussain T, Mustafa SJ. Relaxation of rat aorta by adenosine in diabetes with and without hypertension: role of endothelium. Eur J Pharmacol. 2001;412:51-9.

37. Bardell AL, MacLeod KM. Evidence for inducible nitric-oxide synthase expression and activity in vascular smooth muscle of streptozotocindiabetic rats. J Pharmacol Exp Ther. 2001;296:252-9.

38. Nagareddy PR, McNeill JH, MacLeod KM. Chronic inhibition of inducible nitric oxide synthase ameliorates cardiovascular abnormalities in streptozotocin diabetic rats. Eur J Pharmacol. 2009;611:53-9.

39. Ding M, Lei J, Han H, Li W, Qu Y, Fu E, Fu F, Wang X. SIRT1 protects against myocardial ischemia-reperfusion injury via activating eNOS in diabetic rats. Cardiovasc Diabetol. 2015;14:143.

40. Guo J, Breen DM, Pereira TJ, Dalvi PS, Zhang H, Mori Y, Ghanim H, Tumiati L, Fantus IG, Bendeck MP, Dandona P, Rao V, Dolinsky VW, Heximer SP, Giacca A. The effect of insulin to decrease neointimal growth after arterial injury is endothelial nitric oxide synthase-dependent. Atherosclerosis. 2015:241:111-20.

41. House LM 2nd, Morris RT, Barnes TM, Lantier L, Cyphert TJ, McGuinness OP, Otero YF. Tissue inflammation and nitric oxide-mediated alterations in cardiovascular function are major determinants of endotoxin-induced insulin resistance. Cardiovasc Diabetol. 2015;14:56.

42. Tessari $P$, Cecchet $D$, Cosma A, Vettore M, Coracina A, Millioni R, lori E, Puricelli L, Avogaro A, Vedovato M. Nitric oxide synthesis is reduced in subjects with type 2 diabetes and nephropathy. Diabetes. 2010;59:2152-9.

43. Lee JG, Kang DG, Yu JR, Kim Y, Kim J, Koh G, Lee D. Changes in adenosine deaminase activity in patients with type 2 diabetes mellitus and effect of DPP-4 inhibitor treatment on ADA activity. Diabetes Metab J. 2011;35:149-58.

44. Dubey RK, Mi Z, Gillespie DG, Jackson EK. Dysregulation of extracellular adenosine levels by vascular smooth muscle cells from spontaneously hypertensive rats. Arterioscler Thromb Vasc Biol. 2001;21:249-54.

\section{Submit your next manuscript to BioMed Central and we will help you at every step:}

- We accept pre-submission inquiries

- Our selector tool helps you to find the most relevant journal

- We provide round the clock customer support

- Convenient online submission

- Thorough peer review

- Inclusion in PubMed and all major indexing services

- Maximum visibility for your research

Submit your manuscript at www.biomedcentral.com/submit
() Biomed Central 